Journal of Advanced College of Engineering and Management, Vol. 6, 2021

\title{
PUBLIC TRANSPORTATION OPTIMIZATION ON GODAWARI TO BUDANILKANTHA ROUTE VIA INTRODUCTION OF BUS RAPID TRANSIT
}

\author{
Sandip Acharya ${ }^{1}$, Sagar Upreti², Sandeep Jha ${ }^{3}$, \\ Ananda Marasani ${ }^{4}$, SuyogKattel ${ }^{5}$, HemantTiwari ${ }^{6}$ \\ Sanddipacharya12@gmail.com \\ Students, Department of Civil Engineering \\ Advanced college of Civil Engineering, T.U.
}

\begin{abstract}
Kathmandu is Rapidly growing city where the Crisis due to centralization is foreseen in Transportation sector due to lack of proper Planning and Vision prior of establishing settlement. The Current status of Transportation system in Kathmandu is quite alarming in absence of well-organized Public Transportation system. The growth of Vehicles and simultaneously lack of improvements of existing facilities and traffic management have resulted in unorganized improvement of Traffic thereby increasing congestion, accidents and decrease in vehicle speed affecting road capacity. So using managed Scientific system to decrease jam causing parameters with most planned system and replacing the existing Systems by modern facilities, the problem can be reduced. Introduction of Bus rapid transit by gradual replacement of old transportation systems by providing a bus lane can be promising remedial measure to optimize public transportation system in Kathmandu valley
\end{abstract}

Keywords: Optimization; Causes; Public Transportation; Remedial measures; Jam; Planning; Kathmandu

\section{Background}

Several reasons justify the present condition of Public transportation is not satisfactory inside Kathmandu. People residing on valley are choosing private means of transportation over the public transportation even it is the expensive means. People are trading their cost for other aspects like time, comfort, safety, which is not so assuring in our present public transportation. On studying the mentality of public upon the context of traffic problem in the valley, everyone has one answer and that is expansion and improvement in fixed facilities. That does not answer the whole question, expansion is not always the answer even if it is that is not the logically and economically the best answer. Proper management of fixed Facilities and flow entity and logical coordination between them to have maximum output are the answer.

Godawari to Budanilkantha road section is backbone for the transportation system within Kathmandu city as it touches the two districts namely Lalitpur and Kathmandu. It also passes through the business center namely Sundhara and Ratnapark. All modes of transportation available within valley have participation in this road section. It incorporates from microbuses to buses and three wheelers like tempos and even big Buses. To overcome the unmanaged and congested public transportation, the study aims to study for the proper maintenance of the public transportation system. Mass transit system with fast and reliable system is necessary and BRT can be a good Promising solution.

\section{Methodology}

Available data from the Study at various road Segments was used to analyze the status of delays, jam, travel time, vehicle accessibility. From literature review two vehicle Committee were found and later from field additional two Committee were noted making 4 major service providing vehicle Committee. Data collected from field like Passenger occupancy, speed and delay, travel time were used to find out the present accessibility condition of Godawari to Budanilkantha section where as BRT manual was used to analyze Load factor, Corridor capacity, Service frequency, Stopping Bays, Bus Lane and Bus 
types. Field survey and direct interview with Road users, drivers and passengers was done to get all types of data in various sections. Direct field survey was done to collect data at both sides at more than 25 road section. Volume count survey was used to analyze present Travel condition and present serviceability, Speed and delay study was used to find travel and journey time, Economic analysis is done to check the viability and affordability.

A number of Questionnaires were Circulated to the students, various types of employers, drivers and traffic authorities by using simple random sampling. questionnaires were received and analyzed by various techniques. Data obtained from secondary sources were analyzed using My Track to find out condition and service usability of public transportation.

\section{Data Analysis}

Microsoft Excel, GIS and My Track were used to analyze data. The primary data obtained from the field study and secondary data collected from various sources were processed and analyzed using Excel. For the analysis of quantitative data, MS Excel was extensively used. For the station fixation and its location, My Track (a Google app) and GIS were used.

\section{Findings}

After the analysis we come to conclude the essence of Mass transit is to be adopted at any cost to minimize the delays and jams. After Economic Analysis of Light Rail transit (LRT), Bus Rapid transit (BRT), Ropeway possibility, we come to find feasibility of BRT. We Proposed 73 vehicles to be operating in the study area Godawari to Budanilkantha. Each vehicle leaving at interval of two minutes and so is proposed having the fare of NRs 30 as shown in economic analysis in detail. This mass transit system should be widely adopted considering public sector, Government sector with possibility PublicPrivate-Partnership (PPP).

\section{Corridor capacity and service frequency}

The corridor capacity is defined as the number of passengers traveling in fixed direction in one hour in same system of Public Transportation system. Its unit is pphpd (passenger per hour per direction). Corridor capacity=Vehicle capacity*Load factor*Service frequency*No. of stopping Bays. Load factor is taken $80 \%$, stopping bays at each station is assumed to be 1 . So having corridor capacity from data as calculated in table below service frequency is calculated as:

\begin{tabular}{|l|c|c|c|}
\hline \multicolumn{3}{|c|}{ Peak Hour } \\
\hline Category & No. & Passenger & Total No. Of Passenger \\
\hline Bus & 36 & 48 & 1728 \\
\hline Sajha & 7 & 85 & 595 \\
\hline Micro Bus & 64 & 28 & 1792 \\
\hline Total & & & 4115 \\
\hline
\end{tabular}

Corridor Capacity $=4115 \mathrm{pphpd}$

Load Factor $=0.8$

$4115=160 * 0.8 *$ Service frequency $* 1$

Service frequency $=33$ Vehicle/ hour

i.e. 36 vehicles in an hour

Time Interval $=60 / 33$ (minutes) $=1.82$ minute 


\section{Analysis from flow calculations and Outcome}

At present condition the maximum of flow occurs in morning and evening peak time. The bar shows average flow of passengers in Godawari to Budanilkantha at different time

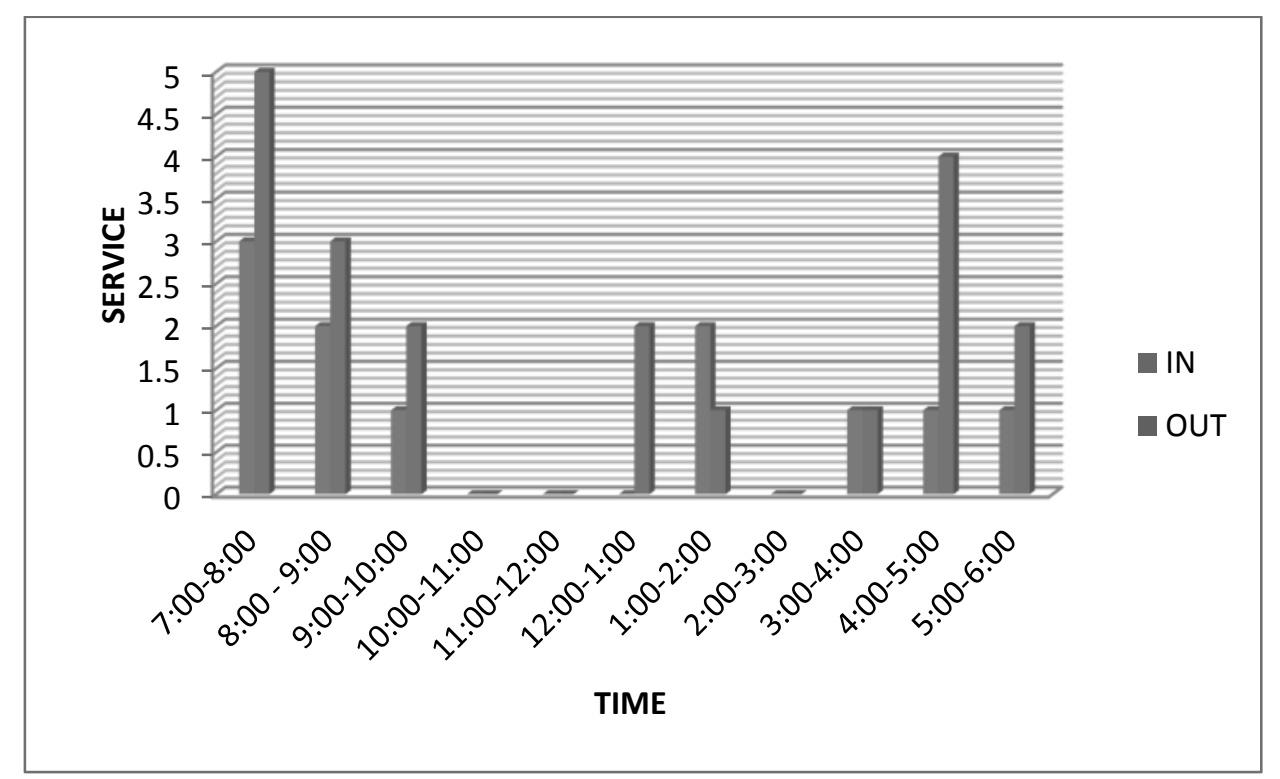

During the study for the completion time to travel the proposed road section takes an average of 120 minutes( 2 hours) for complete trip Godawari to Budanilkantha with an average delay of 29 minutes with speed limit adopted of $40 \mathrm{Km} / \mathrm{hr}$.:

Usually $10 \%$ extra Buses are required as Backup which may be used when certain vehicle need maintenance, repair on when certain bus are behind the schedule. So, for required considering backup are tabulated as below:

\begin{tabular}{|c|c|c|c|}
\hline $\begin{array}{c}\text { Load } \\
\text { Factor }\end{array}$ & $\begin{array}{c}\text { Godawari- } \\
\text { Budanilkhantha }\end{array}$ & Budanilkantha-Godawari & Total including $10 \%$ Backup \\
\hline 0.8 & 36 & 30 & 73 \\
\hline
\end{tabular}

Figure 1 reveals that poor site management and supervision by contractors, large number of work in hand, external causes such as strikes, Nepal bandh, extreme weather conditions and ineffective pre execution planning and lack of timely decision, lack of coordination between various government agencies seems to be prominent cause of delay in bridge construction project of Postal Highway Project.

\section{Analysis of Questionnaire Survey}

500 no. of questionnaire were distributed. Among them 384 questionnaires $(77.4 \%)$ were received. The summary of questionnaire is as:

- Necessity of regular Cleanliness on bus.

- Uniformity of fare charge with compulsion of ticketing system for each age group of passengers.

- Total volume of buses and microbuses is insufficient based on demand of ringroad passenger.

- Video and audio materials presented should be well censored i.e. acceptable for all age groups.

- Unnecessary speeding and stopping of some buses created lot of problem for 


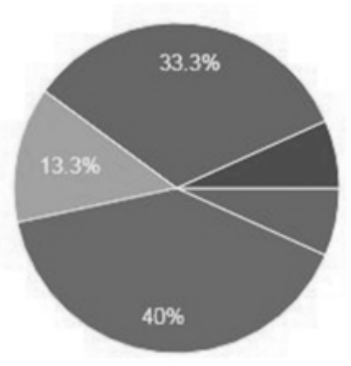

From questionnaire we collected weekly usability, daily usability of public transport and causes of delays experienced and suggestions.

\section{Economic analysis}

Our analysis found Light rail transit is 43 times expensive than Bus Rapid Transit, so we analyze detail economic analysis and payback period of BRT

Fare analysis $=21.49 \mathrm{NRS}$ (per trip)

Proposed Fare $=30 \mathrm{NRS}$ (per trip)

Cost of the bus $=$ US\$260000 $=$ NRS 2010062600

Bank interest rate for the loan $=10 \%$

Passengers per day $=110984$

Taking fare to be Rs 30 including profit on each passenger $=$ Rs 8

Per year fare calculation $=$ Rs $8 * 110984 * 365$

$$
=\text { Rs324073280 }
$$

Daily interest of yearly interest $=(1+.05)^{1 / 365}=1.000133681$

Calculation of Break - Even point

$$
2010062600 *(1+0.1)^{\mathrm{N}}=324073280\left((1+0.00013368)^{365}-1\right) / 0.00013368
$$

Solving this, we get $\mathrm{N}=43.01$ years

\section{Reliability of Research Instrument}

All the data collected were highly accurate based on environmental conditions in both peak and offpeak hour. The analysis part is completed done using BRT Planning manual 2007. Assumptions of various factors and rates were used as per norms of Department of road (DOR) and DOLIDOR criteria. Outcomes of the research can be widely used to analyze similar cities and areas. 


\section{Conclusions}

Jam \&amp; Congestion is adding agony to the passengers. During our study, we found that the stretch of the from Godawari to Budhanilkantha. During the study for the completion time to travel the proposed road section takes an average of 120 minutes(2 hours) for complete trip Godawari to Budanilkantha with an average delay of 29 minutes. The existing delay was due to operational delay \& fixed delay including jam at various sections. There are all together 80 stations were found in our study. But the number of stations should be reduced for the efficient operation and based on our study. Based on the average number of passengers in and out in each station and the corresponding distance between the two stations we have reduced the no. of stations to 66in short term approach. From the passenger occupancy survey, we have calculated the average number of passengers in and out in hourly basis for which includes peak hour and off-peak in both direction of weekdays and supposed to include that value for weekend also.

\section{Recommendations}

Based on the findings of the research, following recommendations are drawn for optimizing public Transportation and minimizing delays:

(1)The record should be properly managed with the allocation of Management Information System (MIS) in each concerned authority.(2)The present transportation system prevalent in the proposed road should be properly supervised, controlled, and must be made systematic by concerned authorities.(3)There should be uniformity of fare charge with compulsion of ticketing system for each age group of passengers.(4)Total volume of 70 articulated bus maybe insufficient based on demand of road passenger in future time as future demand forecasting was not done. Hence, extra buses might need to be purchased in coming future.(5)First and foremost, there should be fixation of Bus Rapid Transit stations of short term with forecast of long term station in every location of the proposed route. 


\section{References}

1. E. Schofer and B. M. Levin, "The urban transportation planning process," Socio-Economic Planning Sciences, vol. 1, no. 2, pp. 185-197, Dec. 1967.

2. Nueery Haque, Nuzhat \& Halder, Sanchari\& Islam, Md\& Nag, Rana \& Alam, Md. Ridwan \& Mehedi Hassan, Md. (2013). "Traffic Volume Study."

3. Christoffel Venter, Gail Jennings, Darío Hidalgo, Andrés Felipe Valderrama Pineda. (2018) The equity impacts of bus rapid transit: A review of the evidenceand implications for sustainable transport. International Journal of Sustainable Transportation 12:2, pages 140-152.

4. Lutfi Prayogi. (2018) "Bus Rapid Transit system's influence on urban development: An inquiry to Boston and Seoul BRT systems' technical characteristics." IOP Conference Series: Earth and Environmental Science 126, pages 012047.

5. Black, Alan (1995). “Urban Mass Transportation Planning." New York: McGraw-Hill

6. Gray, George \& Lester Hoel, eds. (1991). "Public Transportation: Planning, Operation and Management.” Englewood Cliffs, NJ: Prentice-Hall

7. Vuchic, Vukan R. (1981). "Urban Public Transportation Systems and Technology.” Englewood Cliffs, NJ: Prentice-Hal

8. C E G Justo and S K Khanna, "Highway Engineering, Khanna Publications" NewDelhi, India.

9. "Bus Rapid Transit Planning Guide" (2007).

10. Hemantet .al. "Final Year Project Report on Introduction of BRT in Ring Road, Kathmandu Valley, $2011 "$

11. JICA,"The Study for Karachi Transportation Improvement Project In The Islamic Republic Of Pakistan, Vol II."'(2012)

12. The Institute for Transportation and Development Policy. "Pre-Feasibility Study for Bus Rapid Transit Hyderabad, Andhra Pradesh, Final Draft.” Institute of Transportation and Development, Hyderabad.(2005)

13. JICA. "Study on Earthquake Disaster Mitigation in Kathmandu Valley."(2002)

14. "National Population Census" 1991, 2001 and 2011.

15. "Public Transportation in Kathmandu Valley-Restructuring and Reforming the System" (downloaded from www.cen.org.np)

16. JICA "Data Collection Survey on Traffic Improvement in Kathmandu Valley" October 2012

17. Puja et.al "Public Transportation Management along Kathmandu Ring Road with introduction of Bus Rapid Transit(BRT) System, 2017" 